\title{
Surface radiation during the total solar eclipse over Ny-Ålesund, Svalbard, on 20 March 2015
}

\author{
Marion Maturilli and Christoph Ritter \\ Alfred Wegener Institute, Helmholtz Centre for Polar and Marine Research, Potsdam, 14473, Germany \\ Correspondence to: Marion Maturilli (marion.maturilli@awi.de)
}

Received: 11 January 2016 - Published in Earth Syst. Sci. Data Discuss.: 25 January 2016

Revised: 7 April 2016 - Accepted: 15 April 2016 - Published: 22 April 2016

\begin{abstract}
On 20 March 2015, a total solar eclipse occurred over Ny-Ålesund ( $\left.78.9^{\circ} \mathrm{N}, 11.9^{\circ} \mathrm{E}\right)$, Svalbard, in the high Arctic. It was the first time that the surface radiation components during the totality of a solar eclipse were measured by a Baseline Surface Radiation Network (BSRN) station. With the Ny-Ålesund long-term radiation data set as background (available at doi:10.1594/PANGAEA.150000), we present here the peculiarities of the radiation components and basic meteorology observed during the eclipse event. The supplementary data set contains the basic BSRN radiation and surface meteorological data in $1 \mathrm{~min}$ resolution for March 2015, and is available at doi:10.1594/PANGAEA.854326. The eclipse radiation data will be a useful auxiliary data set for further studies on micrometeorological surface-atmosphere exchange processes in the Svalbard environment, and may serve as a test case for radiative transfer studies.
\end{abstract}

\section{Introduction}

At the high-Arctic site $\mathrm{Ny}$ - $\AA$ lesund $\left(78.9^{\circ} \mathrm{N}, 11.9^{\circ} \mathrm{E}\right)$ on the archipelago of Svalbard, surface radiation measurements operated by the Alfred Wegener Institute since 1992 are contributed to the Baseline Surface Radiation Network (BSRN). The measurements include the various parameters related to solar radiation: global and reflected radiation (downward and upward shortwave radiation, $\mathrm{SW}_{\text {down }}$ and $\mathrm{SW}_{\text {up }}$, respectively), as well as the direct and diffuse shortwave radiation $\left(\mathrm{SW}_{\text {direct }}\right.$ and $\mathrm{SW}_{\text {diffuse, }}$ respectively). Furthermore, the upward and downward thermal radiation components, $\mathrm{LW}_{\text {up }}$ and $\mathrm{LW}_{\text {down }}$, are obtained. Detailed information about the instrumental setup and the long-term radiation observations since 1992 is given in Maturilli et al. (2015).

On 20 March 2015, the rare astronomical event of a total solar eclipse occurred over $\mathrm{Ny}$-Ålesund with about 2 min of totality, allowing, for the first time, the measurement of the corresponding special radiation conditions by a BSRN station. The eclipse was no. 61 in Saros cycle 120. Solar eclipses have inspired several earlier investigations in the field of meteorology. Surface atmospheric pressure fluctuations have been observed in connection with solar eclipses caused by the cooling of the atmosphere during the eclipse shadow period (Anderson et al., 1972; Anderson and Keefer, 1975). The pressure perturbations and induced gravity waves generated by a solar eclipse have been studied for several eclipse events (e.g. Schödel et al., 1973; Goodwin and Hobson, 1978; Seykora et al., 1985; Marty et al., 2013). Gravity wave forcing by a solar eclipse has also been found related to ozone photochemistry in the middle atmosphere (Fritts and Luo, 1993). In the planetary boundary layer, the observed effects of a solar eclipse include the modulation of surface fluxes and a reduction in turbulence intensities. The influence of the eclipse shadow on the surface energy budget has been analysed in various climate zones, but so far never in the Arctic. Micrometeorological measurements during total solar eclipse events in the mid-latitudes revealed a decrease in the turbulent fluxes with reduced values of turbulent kinetic energy caused by the eclipse shadow (Foken et al., 2001; Founda et al., 2009). An effect on the vertical temperature structure towards boundary layer stability was found during a total solar eclipse in the tropical convective zone (Rao et al., 2013). Likewise, a transformation in the stability of the nearsurface air during an eclipse event producing atmospheric conditions similar to the initiation of a nocturnal inversion was observed in a desert zone (Eaton et al., 1997). Due to the 


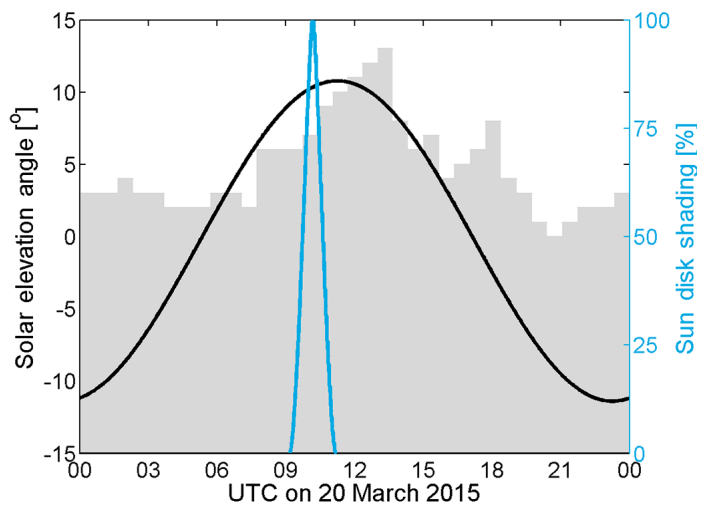

Figure 1. Solar elevation angle (black line) for Ny-Ålesund coordinates $\left(78.9^{\circ} \mathrm{N}, 11.9^{\circ} \mathrm{E}\right)$ on 20 March 2015 , with local horizontal line (grey shading). The totality of the solar eclipse is indicated (cyan line).

sparseness of observational sites in high northern latitudes, no Arctic observations of radiation and micrometeorology in eclipse conditions exist so far.

Here, we present the complete set of surface radiation components and meteorological mast observations with 1 min time resolution during the total solar eclipse event over Ny-Ålesund on 20 March 2015. This high-resolution eclipse data set is intended as a baseline for, for example, further micrometeorological studies analysing the sensitivity of the surface energy balance on abrupt changes of the surface radiation budget. Moreover, a solar eclipse is an excellent means to test radiative transfer models (Emde and Mayer, 2007). The Ny-Ålesund solar eclipse data set is available at the PANGAEA data repository under doi:10.1594/PANGAEA.854326.

\section{Radiative and meteorological conditions on 20 March 2015}

As Ny-Ålesund is located at $78.9^{\circ} \mathrm{N}$, the site is affected by polar day and polar night conditions from 18 April to $24 \mathrm{Au}-$ gust and from 24 October to 18 February, respectively. On 20 March, the diurnal cycle is characterized by regular day and night-time conditions, with the sun about $12 \mathrm{~h}$ above the horizon (Fig. 1). Yet, as Ny-Ålesund is situated on the coastline with mountains to the south, the complex horizontal line (doi:10.1594/PANGAEA.669522) prevents direct sun visibility for some parts of the day. The solar eclipse though occurred when the sun was above the mountains, allowing observations of the partial and total solar eclipse phases.

On 20 March 2015, solar observations in Ny-Ålesund were undisturbed in terms of cloudiness. The cloud base height measured by remote sensing with a Vaisala CL51 ceilometer (doi:10.1594/PANGAEA.854330) is shown in Fig. 2a. Clearly, the early morning cloud cover on 20 March 2015 had vanished before daylight and the beginning of the so-
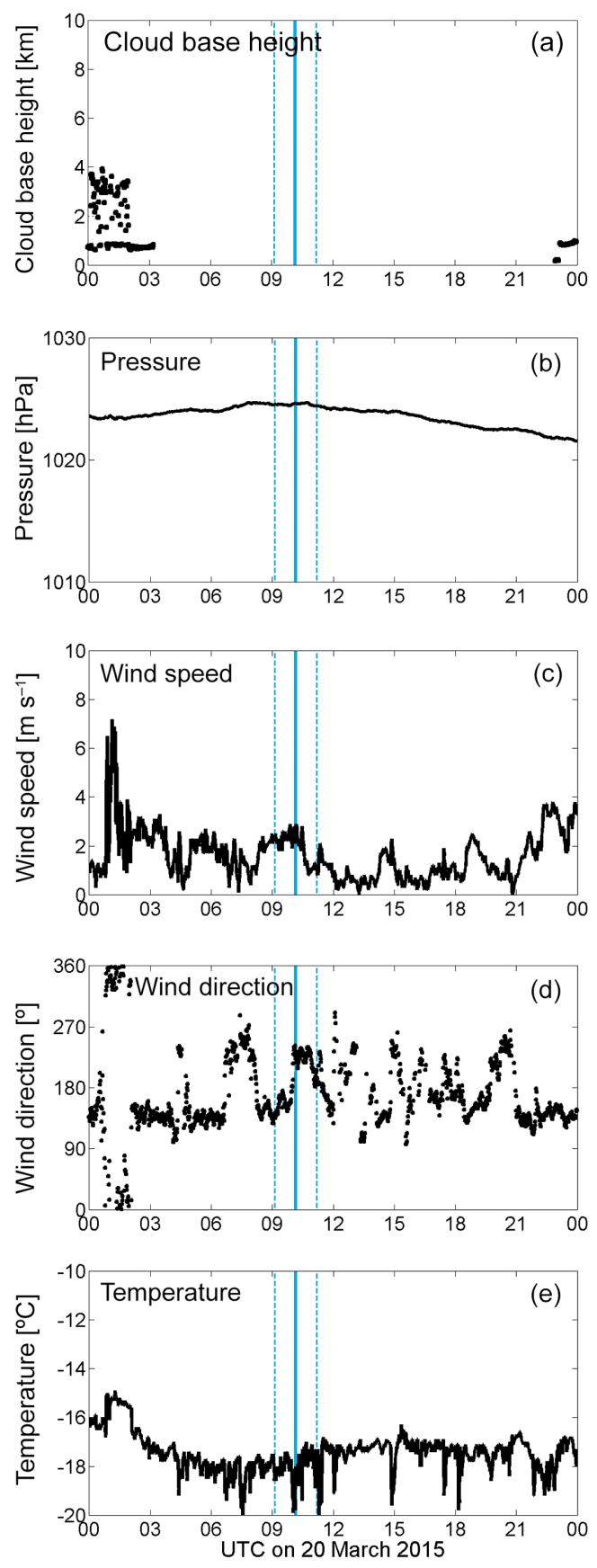

Figure 2. Meteorological surface observations in Ny-Ålesund on 20 March 2015, with (a) cloud base height, (b) station level pressure, (c) $10 \mathrm{~m}$ wind speed, (d) $10 \mathrm{~m}$ wind direction, and (e) surface air temperature at $2 \mathrm{~m}$ height. Indicated is the duration of the solar eclipse (dashed blue lines) and the time of total eclipse (blue line).

lar eclipse, allowing perfect clear-sky observation conditions. Only at about 23:00 UTC were low clouds again observed above the station. In fact, the synoptic situation on 20 March 2015 was very stable under the influence of a highpressure system centred over the Greenland Sea. The station level pressure was changing only marginal, with a max- 


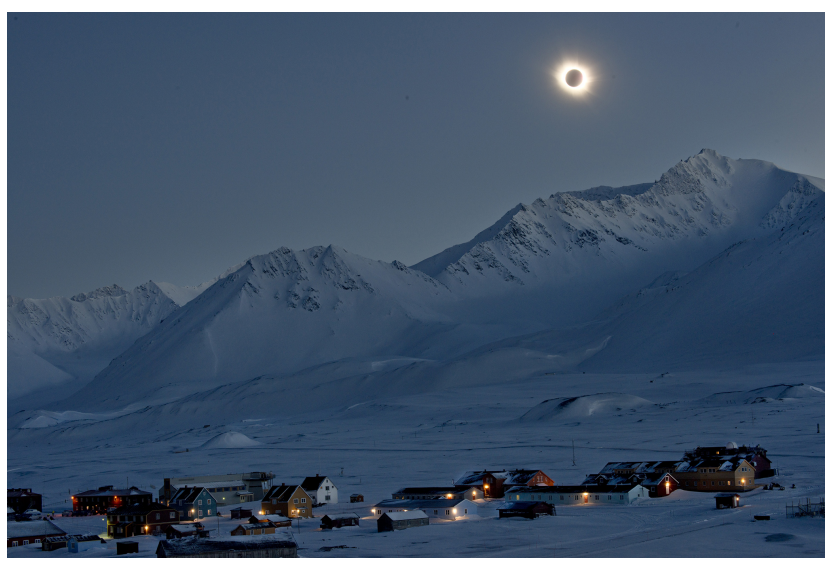

Figure 3. Solar eclipse over Ny-Ålesund, Svalbard. (Photo: Nathalie Grenzhaeuser)

imum of $1024.7 \mathrm{hPa}$ at about 10:40 UTC slowly decreasing by about $3 \mathrm{hPa}$ within the next $12 \mathrm{~h}$. Without synoptic drag on the lower atmospheric wind field, the local conditions dominated the near-surface wind. Throughout the clear-sky phase of the day, the wind speed was very low below about $3 \mathrm{~m} \mathrm{~s}^{-1}$ (Fig. 2c). In the Ny Ålesund surroundings, these are favourable conditions for prevailing katabatic winds from the glaciers (Jocher et al., 2012). In these cases, the common south-east-oriented near-surface atmospheric flow along the fjord axis (Beine et al., 2001; Maturilli et al., 2013) is often interrupted by south-westerly katabatic winds from the mountains and glaciers south of Ny-Ålesund, bringing cold air to the station. On 20 March 2015, such cold air outflow events are reflected in the surface air temperature (Fig. 2e). Being about $2{ }^{\circ} \mathrm{C}$ higher in the presence of clouds in the early morning hours, the baseline temperature is rather stable around -18 to $-17^{\circ} \mathrm{C}$ during the rest of the day. Yet, short peaks of lower temperatures are observed. These are correlated with associated changes in wind direction (Fig. 2d), pointing to cold air advection to the station when the wind arrives from south-west, the direction of the Brøggerbreen glacier. Overall, the meteorological conditions for the observation of the total solar eclipse on 20 March 2015 in NyÅlesund were excellent. The detailed surface radiation measurements during the eclipse are described in the next section.

\section{Surface radiation measurements during the solar eclipse}

In Ny-Ålesund, the solar eclipse on 20 March 2015 started at 09:10 UTC and lasted until 11:11 UTC, with the total eclipse phase between 10:09:53 and 10:12:11 UTC. The event was followed by instrumentation and by eye, and its spectacular view is shown in Fig. 3.

The measured diurnal cycle of global radiation for 20 March 2015 is shown in Fig. 4. Though clouds were not

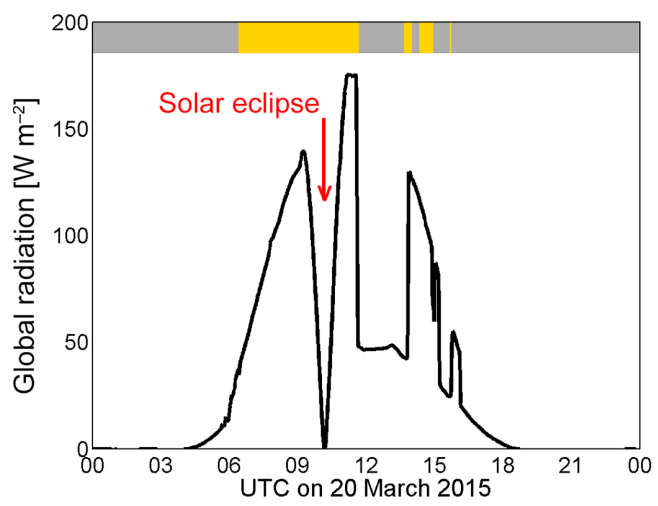

Figure 4. Ny-Ålesund global radiation $\left(\mathrm{SW}_{\text {down }}\right)$ on 20 March 2015, measured by a Kipp \& Zonen pyranometer CMP22. The colour bar indicates the periods when the sun elevation was above the horizontal line (yellow) or the instruments were shaded by mountains (grey).

present during the sunlit part of the day, broad reduction in global radiation is observed while the sun is shaded by the mountains, as illustrated in Fig. 1 and indicated in Fig. 4. During the total phase of the solar eclipse, the global radiation vanishes completely, generating a unique signal in the measured downward radiation.

The downward radiation components and the upward longwave radiation during the eclipse phase are shown in Fig. 5. One quality control factor of BSRN sites is the availability of independent measurements of direct and diffuse radiation in addition to the global radiation. In Ny-Ålesund, the direct radiation is measured by a Kipp \& Zonen CHP1 pyrheliometer on a Schulz \& Partner solar tracker shared with the diffuse radiation measurement by a ball-shaded Kipp \& Zonen CMP22. Global and reflected radiation is also detected by CMP22 instruments, while upward and downward longwave radiation are obtained by Eppley PIR pyrgeometers (Maturilli et al., 2015).

The direct radiation normalized to the horizontal plane, the diffuse radiation, and the global radiation are shown in the upper panel of Fig. 5, complemented by the downward thermal radiation. The eclipse event emerges symmetrically in the shortwave radiation components, following the solar disk shading by the moon. The largest contribution to the global radiation is given by the direct radiation component, constituting about two-thirds of the incoming shortwave radiation. The contribution by the diffuse radiation is, on the one hand, limited by the mountain surroundings as indicated by the horizontal line in Fig. 1. On the other hand, the mountains are snow-covered and thus contribute to the incoming diffuse radiation by reflection.

On 20 March 2015, the ground underneath the radiation instrumentation setup was also snow-covered, with a snow layer of about $30 \mathrm{~cm}$ height as measured by a Jenoptik snow depth sensor SHM30. As low solar elevation angles 

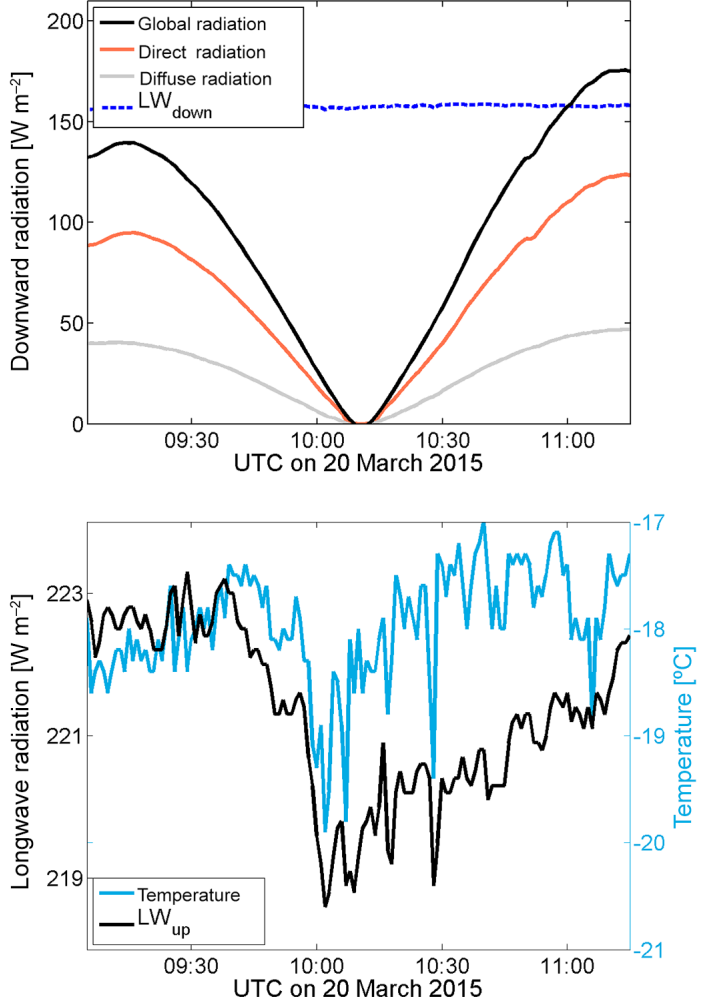

Figure 5. The downward radiation components' shortwave direct, diffuse, and global radiation as well as downward thermal radiation (upper panel), and the upward thermal radiation $\mathrm{LW}_{\mathrm{up}}$ and $2 \mathrm{~m}$ temperature (lower panel) between 09:10 and 11:10 UTC on 20 March 2015 in Ny-Ålesund.

limit the reliability of the albedo retrieval, the albedo value $\mathrm{SW}_{\mathrm{up}} / \mathrm{SW}_{\text {down }}=0.7$ found for the highest solar elevation on 20 March 2015 remains subject to high uncertainty. The resulting emitted upward longwave radiation is shown in the lower panel of Fig. 5. As the emission of thermal radiation is temperature-dependent, the course of the upward longwave radiation during the solar eclipse is not symmetrical. With the progression of the solar eclipse and the consequent reduction in downward shortwave radiation, the thermal cooling of the snow surface becomes predominant. As a consequence, a decrease in upward longwave radiation related to surface and/or near-surface cooling was observed. The longwave radiation measurements are temperature-corrected with three internal temperature sensors that confirm the radiative cooling and indicate that the decrease in upward longwave radiation is not caused by changes in air temperature due to advection. Instead, a decrease in the $2 \mathrm{~m}$ temperature is observed with about 10 min delay to the decreasing $\mathrm{LW}_{\mathrm{up}}$. This cooling, however, is potentially related to the advection of colder air from the glacier since it occurs simultaneous to a change in wind direction (see Fig. 2d). As periods with prevailing katabatic winds from the glaciers were observed throughout the day, the changing wind and air temperature conditions can-

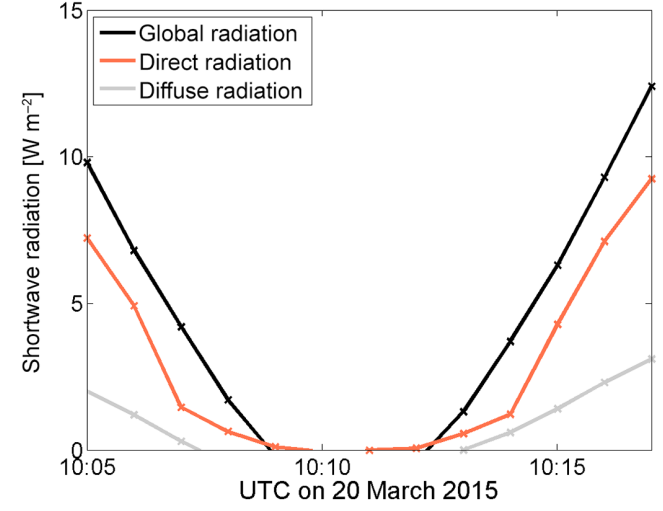

Figure 6. The downward shortwave radiation components' direct, diffuse, and global radiation during the total eclipse phase.

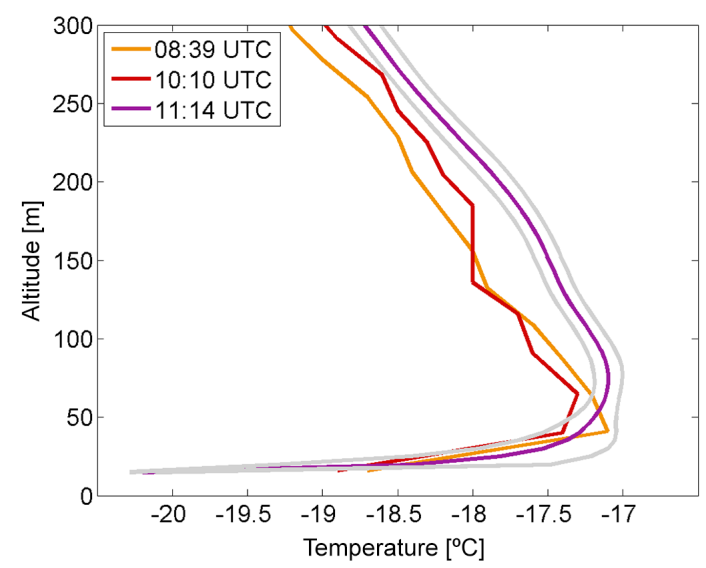

Figure 7. Vertical temperature profiles measured by RS92 radiosondes launched from Ny-Ålesund on 20 March 2015. The radiosonde launched at 11:14 UTC has been processed as a GRUAN reference sonde, and the corresponding temperature profile (purple line) is provided with measurement uncertainty in each altitude level (grey lines).

not unambiguously be attributed to the solar eclipse. With the returning sunlight after the total eclipse phase, the upward longwave radiation also gently inclines to reach its original level.

Close to the total eclipse phase, more measurement details of the shortwave radiation components become apparent (Fig. 6). It turns out that the independent global radiation measurement falls to $0 \mathrm{~W} \mathrm{~m}^{-2}$ in minutes 10:09 to 10:12 UTC, i.e., shortly before and shortly after the actual totality when considering minute mean values. In fact, for the small irradiance values during the eclipse, the accuracy of the instruments needs to be taken into account. For the CMP22 used for the global radiation measurement, the zerooffset type A due to the inner dome having a different temperature from the cold junctions of the sensor is given at $<3 \mathrm{~W} \mathrm{~m}^{-2}$ by the manufacturer, as well as a directional response $<5 \mathrm{~W} \mathrm{~m}^{-2}$. These effects may also affect the mea- 
surement of diffuse radiation with a similar CMP22. The values for the diffuse radiation drop to $0 \mathrm{~W} \mathrm{~m}^{-2}$ even earlier and then rise later, which is probably also related to the fact that the pyranometer for the detection of diffuse radiation is shaded by a ball slightly larger than the sun disk, thus covering a small fraction of the sky that is still visible for the global radiation measurement. The signal of direct shortwave radiation detected by pyrheliometer vanishes for the shortest period.

\section{Atmospheric profiles}

Three Vaisala RS92 radiosondes were launched from $\mathrm{Ny}$ Ålesund during the eclipse period on 20 March 2015, at 08:39, 10:10, and 11:14 UTC. The Ny-Ålesund radiosonde programme is certified by the Global Climate Observing Systems (GCOS) Reference Upper-Air Network (GRUAN), providing radiosonde data in reference quality. The radiosonde launched at 11:14 UTC has therefore been processed by GRUAN, and the data are available with quantitative uncertainty values for every measurement point (doi:10.5676/GRUAN/RS92-GDP.2).

The temperature profiles in the lowermost $300 \mathrm{~m}$ of the atmosphere are shown in Fig. 7. As the balloons have an ascent rate of $5 \mathrm{~m} \mathrm{~s}^{-1}$, the vertical profiles should be considered snapshots of the atmospheric state. In all profiles, a surface-based inversion below $100 \mathrm{~m}$ altitude indicates stable conditions in the planetary boundary layer. Above the inversion, the temperature decreases more or less following the adiabatic temperature gradient, slightly differing from one profile to the next. Considering the measurement accuracy and the temperature uncertainty shown for the GRUAN processed profile (Fig. 7), potential changes in the altitude of the surface-based inversion top fall within the detection limit of the instrumentation. Overall, no temperature changes in the vertical column can be attributed to the solar eclipse. Before, during, and after the eclipse, the boundary layer was characterized by very stable conditions.

\section{Summary}

Adding to the long-term surface radiation observations from Ny-Ålesund (Maturilli et al., 2015), the rare event of a total solar eclipse was measured by BSRN instrumentation on 20 March 2015. Under favourable meteorological conditions, the eclipse left its imprint on the surface radiation diurnal cycle. The associated data set (doi:10.1594/PANGAEA.854326) provides highest quality measurement data of direct, diffuse, global, and shortwave reflected radiation; upward and downward longwave radiation; and $2 \mathrm{~m}$ temperature, relative humidity, and stationlevel pressure in $1 \mathrm{~min}$ resolution. Embedded in the larger frame of long-term surface radiation monitoring data, the solar eclipse data presented here provide the unique occasion to study the atmospheric response to rapid cut-off and reappearance of shortwave radiation under low solar elevation angles in an Arctic environment. In a larger frame, the data may provide potential benefit to radiative transfer model evaluation or satellite data validation. On a more local scale, the eclipse radiation data complement in situ and remote sensing experiments operated in Ny-Ålesund. As one of the main concerns of current Arctic research is the energy budget at the Earth's surface, the presented surface radiation measurements contribute as a baseline to the various Ny-Ålesund boundary layer studies, including turbulent flux measurements of sensible and latent energy. The surface radiation data may also support the discussion of, for example, a photochemical response in measured atmospheric trace gases, or radiationand temperature-related changes in the fjord's sea surface layer. Overall, the diversity of research at the Arctic research centre Ny-Ålesund offers various possibilities to apply the solar eclipse radiation data for process studies under freeatmospheric laboratory conditions switched to abrupt nighttime conditions.

Acknowledgements. The authors thank the station personnel of the AWIPEV research base in Ny-Ålesund for maintaining the instrumentation and operating the measurements. Particular thanks to S. Debatin for data validation. We thank Nathalie Grenzhaeuser for providing the photo (Fig. 3, copyright Nathalie Grenzhaeuser).

Edited by: A. Kokhanovsky

\section{References}

Anderson, R. C. and Keefer, D. R.: Observation of temperature and pressure changes during 30 June 1973 solar eclipse, J. Atmos. Sci., 32, 228-231, 1975.

Anderson, R. C., Keefer, D. R., and Myers, O. E.: Atmosphericpressure and temperature changes during 7 March 1970 solar eclipse, J. Atmos. Sci., 29, 583-587, 1972.

Beine, H. J., Argentini, S., Maurizi, A., Mastrantonio, G., and Viola, A.: The local wind field at Ny-Ålesund and the Zeppelin mountain at Svalbard, Meteorol. Atmos. Phys., 78, 107-113, doi:10.1007/s007030170009, 2001.

Eaton, F. D., Hines, J. R., Hatch, W. H., Cionco, R. M., Byers, J., Garvey, D., and Miller, D. R.: Solar eclipse effects observed in the planetary boundary layer over a desert, Bound.-Lay. Meteor., 83, 331-346, 1997.

Emde, C. and Mayer, B.: Simulation of solar radiation during a total eclipse: a challenge for radiative transfer, Atmos. Chem. Phys., 7, 2259-2270, doi:10.5194/acp-7-2259-2007, 2007.

Foken, T., Wichura, B., Klemm, O., Gerchau, J., Winterhalter, M., and Weidinger, T.: Micrometeorological measurements during the total solar eclipse of August 11, 1999, Meteorol. Z., 10, 171178, doi:10.1127/0941-2948/2001/0010-0171, 2001

Founda, D., Lykoudis, S., Psiloglou, B. E., Petrakis, M., and Zerefos, C.: Observations of the atmospheric surface layer parameters during the total solar eclipse of March 29th, in Greece, Meteorol. Z., 18, 489-494, doi:10.1127/0941-2948/2009/0406, 2009. 
Fritts, D. C. and Luo, Z. G.: Gravity-wave forcing in the middle atmosphere due to reduced ozone heating during a solar eclipse, J. Geophys. Res., 98, 3011-3021, doi:10.1029/92JD02391, 1993.

Goodwin, G. L. and Hobson, G. J.: Atmospheric gravity waves generated during a solar eclipse, Nature, 275, 109-111, doi:10.1038/275109a0, 1978.

Jocher, G., Karner, F., Ritter, C., Neuber, R., Dethloff, K., Oberleitner, F., Reuder, J., and Foken, T.: The near-surface small-scale spatial and temporal variability of sensible and latent heat exchange in the Svalbard region: a case study, ISRN Meteorology, 2012, 357925, doi:10.5402/2012/357925, 2012.

Marty, J., Dalaudier, F., Ponceau, D., Blanc, E., and Munkhuu, U.: Surface Pressure Fluctuations Produced by the Total Solar Eclipse of 1 August 2008, J. Atmos. Sci., 70, 809-823, doi:10.1175/JAS-D-12-091.1, 2013.

Maturilli, M., Herber, A., and König-Langlo, G.: Climatology and time series of surface meteorology in Ny-Ålesund, Svalbard, Earth Syst. Sci. Data, 5, 155-163, doi:10.5194/essd-5-155-2013, 2013.
Maturilli, M., Herber, A., and König-Langlo, G.: Surface radiation climatology for Ny-Ålesund, Svalbard $\left(78.9^{\circ} \mathrm{N}\right)$, basic observations for trend detection, Theor. Appl. Climatol., 120, 331-339, doi:10.1007/s00704-014-1173-4, 2015.

Rao, K. G., Reddy. N. N., Ramakrishna, G., Bhuyan, P. K., Bhuyan, K., Kalita, G., and Pathak, B.: Near surface atmospheric response to the total solar eclipse at Dibrugarh on 22 July 2009, J. Atmos. Sol.-Terr. Phy., 95-96, 87-95, doi:10.1016/j.jastp.2013.01.001, 2013.

Schödel, J. P., Klostermeyer, J., and Röttger, J.: Atmospheric Gravity Wave Observations after the Solar Eclipse of June 30, 1973, Nature, 245, 87-88, doi:10.1038/245087a0, 1973.

Seykora, E. J., Bhatnagar, A., Jain, R. M., and Streete, J. L.: Evidence of atmospheric gravity waves produced during the 11 June 1983 total solar eclipse, Nature, 313, 124-125, doi:10.1038/313124a0, 1985. 